DIAGNOSIS

\title{
A primary healthcare team had low sensitivity for detecting postnatal depression
}

Hearn G, Iliff A, Jones I, et al. Postnatal depression in the community. Br J Gen Pract 1998 Mar;48:1064-6.

\section{Questions}

Does the use of the Edinburgh Postnatal Depression Scale (EPNDS) at 6-8 weeks postpartum detect women with postnatal depression not previously detected by a primary healthcare team? Can the primary healthcare team as a whole detect more women with postnatal depression in the community than can individual groups of general practitioners, health visitors, or midwives? Can the number of contacts women have with healthcare providers after delivery be used to screen for postnatal depression?

\section{Design}

A blinded comparison of the ability of a primary healthcare team, as a whole and as individual professional groups, and the EPNDS to detect postnatal depression.

\section{Setting}

7 general practices in Bolton, UK.

\section{Participants}

176 mothers who attended their postnatal examination at 6-8 weeks after delivery. Exclusion criteria were an inability to read or speak English, neonatal deaths, or babies with major congenital abnormalities.

\section{Description of test and diagnostic standard}

Health visitors, midwives, and general practitioners recorded the number of routine and non-routine contacts they had with mothers for 42 days after delivery and whether or not they were aware of mental health problems in the mother; these data were collected before the results of the EPNDS were known. The EPNDS, a self report scale with 10 items, has been validated in the community and shown to have $95 \%$ sensitivity and $93 \%$ specificity at a score $>11$.

\section{Main outcome measures}

Sensitivity and specificity for detecting postnatal depression (which was defined as an EPNDS score $\geqslant 12$.)

\section{Main results}

The primary healthcare team as a whole identified more women who were depressed after delivery than did individual professional groups of general practitioners, health visitors, or midwives but the difference was not statistically significant; the sensitivity for detecting postnatal depression was low (table). Women with and without postnatal depression did not differ in the number of contacts they had with healthcare providers $(\mathrm{p}=0.37)$.

\section{Conclusions}

The primary healthcare team had low sensitivity for detecting postnatal depression compared with the Edinburgh Postnatal Depression Scale; the team as a whole did not detect statistically significantly more women with postnatal depression than did individual groups of professionals. The number of contacts with healthcare providers did not differ between women with and without postnatal depression.

Test features for detection of postnatal depression by professional groups of healthcare providers $v$ the Edinburgh Postnatal Depression Scale *

\begin{tabular}{|c|c|c|c|c|}
\hline Professional group & $\begin{array}{l}\text { Sensitivity \% } \\
(95 \% \text { CI })\end{array}$ & Specificity \% (CI) & $+L R$ & $-L R$ \\
\hline General practitioner & $33(17$ to 54$)$ & $96(91$ to 98$)$ & 8.06 & 0.70 \\
\hline Health visitor & $20(7$ to 41$)$ & $93(88$ to 97$)$ & 3.04 & 0.86 \\
\hline Midwife & $21(6$ to 46$)$ & $98(94$ to 100$)$ & 12.42 & 0.80 \\
\hline $\begin{array}{l}\text { Whole primary } \\
\text { healthcare team }\end{array}$ & $43(25$ to 63$)$ & 92 (86 to 96$)$ & 5.27 & 0.62 \\
\hline
\end{tabular}

$*+\mathrm{LR}=$ likelihood ratio for the presence of the disease if the test is positive; $-\mathrm{LR}=$ likelihood ratio if the test is negative. $+\mathrm{LR},-\mathrm{LR}$, and CI calculated from data in article.

\section{Source of funding: none stated.}

For correspondence: Dr I Jones, 639 Chorley New Road, Lostock, Bolton BL6 4AA, UK. Fax +44 (0)1204849469.

\section{Commentary}

The findings by Hearn et al confirm those of other studies that show a substantial number of depressed women will be missed when the clinical impressions of healthcare providers (ie, health visitors, midwives, general practitioners, etc) are the only assessment criterion used. ${ }^{1}$ An added dimension in this study was the investigation of whether the number of contacts with the primary healthcare team could act as a screen for postnatal depression in comparison with the EPNDS.

The value of the EPNDS is now well established. It was specifically designed to detect depression in postpartum women, ${ }^{2}$ and it is increasingly being modified or validated, or both, for use in diverse (including transcultural and Asian) populations,,${ }^{3}$ with good to excellent sensitivity and specificity. ${ }^{3}$

This study has limitations: firstly, the number of contacts is an unreliable indicator of depression because women may contact a healthcare professional postpartum for many reasons. Secondly, as the authors acknowledged, the data were incomplete; for example, midwives assessed fewer women $(n=137)$ than did the primary healthcare team as a whole $(n=176)$. Finally, the choice of a cut off point of $\geqslant 12$ on the EPNDS rather than $\geqslant$ 13, which was used by Cox et al to indicate a probable major depression, ${ }^{2}$ may have led to a higher prevalence of depression in this study.

Depression after birth contributes substantially to maternal morbidity. Detection using the EPNDS, rather than clinical impression, and early intervention have a role in secondary prevention. ${ }^{3}$

Georgina Stamp, RN, RM, PhD Senior Research Fellow

North Western Adelaide Health Service University of South Australia Adelaide, Australia

1 Briscoe M. Identification of emotional problems in postpartum women by health visitors. lems in postpartum women by health visito
Br Med (Clin Res Ed) 1986;292:1245-7.

2 Cox JL, Holden JM, Sagovsky R. Detection of postnatal depression. Development of the 10-item Edinburgh Postnatal Depression Scale. Br J Psychiatry 1987;150:782-6.

3 Cox JL, Holden J. Perinatal Psychiatry: use and misuse of the Edinburgh Postnatal Depression Scale. London: Gaskell, 1994.

4 Lumley J, Small R. Depression after birth: developing methods of transcultural assessment. Annual Report February 1997-January 1998. Melbourne: Centre for the Study of Mothers' and Children's Health, 1998. 